\title{
ADRENOCORTICAL HYPERFUNCTION IN “IDIOPATHIC” HIRSUTISM AND THE STEIN-LEVENTHAL SYNDROME ${ }^{1}$
}

\author{
By T. F. GALlAGHER, ATTALLAH KAPPAS, LEON HELLMAN, M. B. LIPSETT, \\ O. H. PEARSON, AND C. D. WEST
}

(From the Sloan-Kettering Institute for Cancer Research, New York, N. Y.)

(Submitted for publication November 20, 1957; accepted January 16, 1958)

This is a report on a series of 13 women with hirsutism who have been studied with regard to the isolation, characterization and quantitation of their major urinary ketosteroid metabolites. No attempt was made to select the subjects on any basis other than obvious excessive hair growth. By the methods employed $(1,2)$, it has been possible to demonstrate the existence of a specific quantitative alteration in the steroid production of these hirsute women which, as a group, distinguishes them from normal women. The direction and character of this alteration permits the conclusion that in these subjects there was an excessive elaboration of adrenal steroid hormones. Correlation of the presence of hirsutism with known pathways of steroid metabolism in man leads to the interpretation that this excessive hormonal production was in larger measure the adrenal androgen. ${ }^{2}$ A relationship may then exist between a particular type of cortical hyperfunction and hypertrichosis in certain of these women. This conclusion confirms and extends that reached previously in a detailed study of a single patient (3).

Four women with hirsutism, in whom it was later possible to establish the diagnosis of the Stein-Leventhal syndrome, are included in this study. The results of these women were taken into account because the sole criterion of patient selection was hirsutism and there was no doubt about this feature. Since the diagnosis of Stein-

\footnotetext{
1 This investigation was supported in part by a grant from the American Cancer Society and research grants (CY-3207 and C-925) from the National Cancer Institute of the National Institutes of Health, United States Public Health Service.

2 The term "adrenal androgen" is a convenient designation for the steroid hormone (or hormones) produced by the adrenal and metabolized predominantly to androsterone and etiocholanolone. The chemical nature of this component of the adrenal secretion is under active investigation in these laboratories.
}

Leventhal syndrome was unequivocally established only by direct examination of the ovaries, these patients would have been classified as exhibiting hirsutism of undetermined cause if they had not been subjected to laparotomy. Since adrenocortical hyperfunction was evident in each, the results may be considered to support previous speculation concerning the role of the adrenal cortex in the expression of certain of the clinical manifestations of this disorder (4-6).

\section{SUBJECTS AND METHODS}

Thirteen consecutive women seen in the Endocrine Clinic of Memorial Hospital with the problem of hirsutism were studied. They are identified by initial and age. The following urine collections were studied: P17, a 10 day control; L21, a 5 day control and a 1 day period representing the second day of administration of cortisone, $75 \mathrm{mg}$. per day; G24, a 3 day control and a 5 day period on cortisone administration, $50 \mathrm{mg}$. per day ; S24, a 7 day control and a 1 day period representing the second day on hydrocortisone, $120 \mathrm{mg}$. per day; C25, a 5 day control; B25, a 5 day control; K28, a 5 day control; A28, a 2 day control; R32, a 10 day control; C32, a 12 day control; M45, a 1 day control; M50, a 5 day control and a 5 day period representing the last half of a 10 day period on cortisone, $100 \mathrm{mg}$. per day; M62, a 9 day control and a 4 day period representing Days 6 through 9 on cortisone, $75 \mathrm{mg}$. per day. Two normal young women [Subjects M22 and W25 from a previous investigation (2)] received $50 \mathrm{mg}$. of cortisone daily for 6 days.

All patients were referred for study because of longstanding generalized hirsutism of undetermined cause. Breast development was variable but there were no pronounced alterations of body habitus in any subject. There was moderate clitoral enlargement in several but external genitalia were otherwise normal. Sterility was not a problem in the several married patients studied Significant disturbances of the menstrual pattern occurred in only four subjects, P17, L21, S24 and C25. These women complained of severe oligomenorrhea or prolonged periods of amenorrhea. Clinical study here and elsewhere failed to disclose a discrete lesion as a basis for hirsutism in any patient. Because of suggestive clinical features including elevated steroids this 


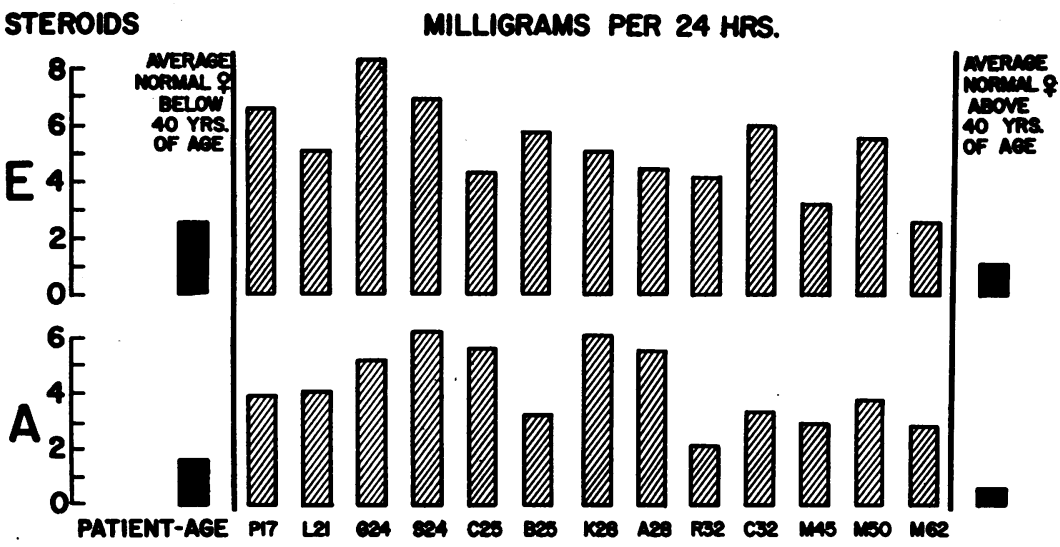

Fig. 1. Production of Androsterone (A) and Etiocholanolone (E) By HiRsute Women Compared with Average Values of Normal Women

study included laparotomy in P17, L21, G24, C25, A28, M45 and M50, in order to eliminate the possibility of adrenal or ovarian tumors. An autopsy examination was performed on M62, who died some time after study. Adrenals and ovaries were felt to be grossly or microscopically normal in all subjects except P17, L21, S24 and C25. In these four women, bilaterally enlarged polycystic ovaries were found similar to those described by Stein and Leventhal (7).

Urine collections were complete as judged by the daily creatinine excretion. As soon as practicable after collection the urinary conjugates were hydrolyzed with enzyme and acid according to Method E (2). Preparation of $\alpha$ and $\beta$ ketonic subfractions was done as previously described (1). The separation of individual components was accomplished exclusively by paper chromatography (2), with identification by means of infrared spectrometry where necessary. The values for each compound are corrected from equivalents of dehydroiso-. androsterone to $\mathrm{mg}$. of the substance measured. Results for each compound are shown in $\mathrm{mg}$. per 24 hours. The average values for normal women are calculated from data published previously (2), which have been confirmed by current studies both as to the range of values reported as well as the depression in 11-desoxy-17-ketos- teroids with age. The following abbreviations are used: A for $3 \alpha$-hydroxyandrostane-17-one (androsterone); E for $3 \alpha$-hydroxyetiocholane-17-one (etiocholanolone); $\mathrm{OH}-\mathrm{A}$ for $3 \alpha, 11 \beta$-dihydroxyandrostane-17-one; OH-E for $3 \alpha, 11 \beta$-dihydroxyetiocholane-17-one; $11=\mathrm{OE}$ for $3 \alpha$ hydroxyetiocholane-11,17-dione; $D$ for $3 \beta$-hydroxy- $\Delta^{5}$ androstene-17-one (dehydroisoandrosterone).

\section{RESULTS}

Figures 1 and 2 show the values for each of the isolated steroids from the hirsute women and average values for normal women below and above 40 years of age. Production of $\mathrm{A}$ and $\mathrm{E}$ by hirsute women in every case exceeded that of normal women of comparable age; in most instances the amounts were comparable to those found in normal men (Figure 3). Considered as a group, the production of $\mathrm{A}$ plus $\mathrm{E}$ in the hirsute women was more than three times that of the average of the normal women of all ages. The average production of A plus $\mathrm{E}$ by the hirsute group below 40 years of age was two and one-half times that of the

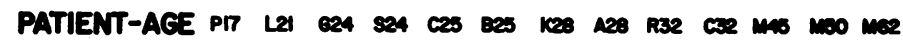

\begin{tabular}{|c|c|c|c|}
\hline STEROADS & POMEN & AMOUNT IN MULIGRAMS & Oras \\
\hline & $\begin{array}{l}0.5 \\
0.4 \\
0.5\end{array}$ & $\begin{array}{llllllllllllll}1.5 & 0.7 & 0.8 & 0.9 & 0.8 & 1.4 & 1.3 & 0.7 & 0.6 & 0.2 & 0.4 & 0.6 & 0.8 \\
0.7 & 0.8 & 1.0 & 0.8 & 0.3 & 1.0 & 1.1 & 0.8 & 1.0 & \text { Tr. } & 0.2 & 0.7 & 0.5 \\
1.3 & 1.4 & 0.7 & 0.7 & 0.8 & 1.4 & 1.6 & 1.0 & 0.8 & \text { Tr. } & 0.3 & 0.6 & 1.4\end{array}$ & $\begin{array}{l}0.5 \\
0.6 \\
0.5\end{array}$ \\
\hline & 0.3 & $\begin{array}{lllllllllllll}5.9 & 0.6 & 0.2 & 1.4 & 2.1 & 4.6 & 0.9 & 2.4 & 0.1 & 5.7 & 0.4 & 0.5 & 0.2\end{array}$ & 0.2 \\
\hline
\end{tabular}

Fig. 2: Production of Major Sterom Hormone Metabolites by Hirsute Women. Compared with Average Values for Normal Women Below and Above 40 YeArs OF AgE 


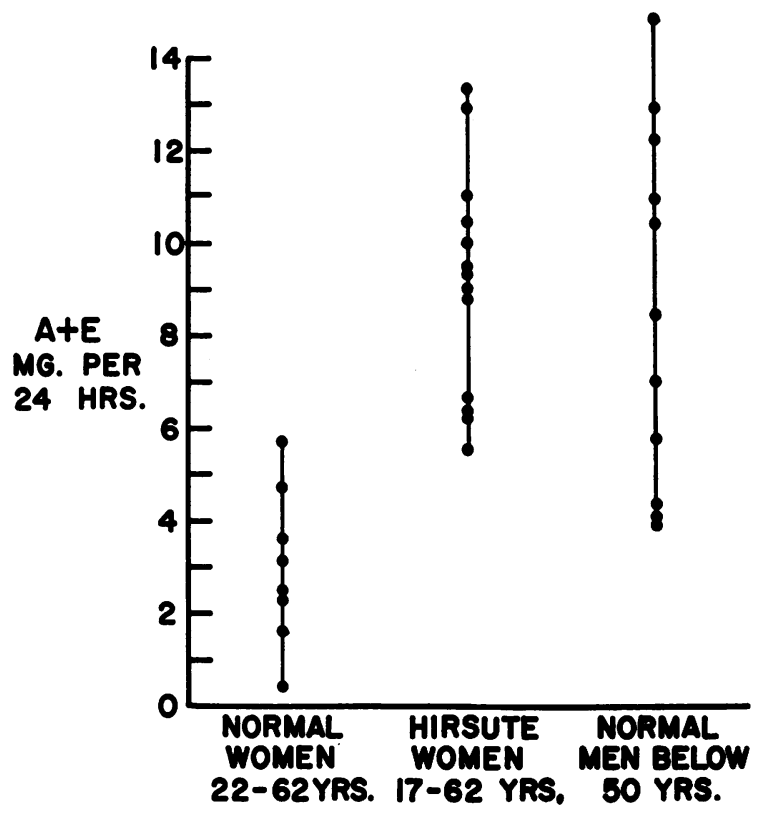

Fig. 3. Range of Values for Androsterone Plus Etiocholanolone (A Plus E) for Hirsute Women Compared with Normal Men and Women

average for the normal women in this age category. The increases in these compounds were variable, ranging from the minimal alterations shown by R32 to the pronounced elevations found with Subjects G24, S24, and K28.

The values for dehydroisoandrosterone (D) are in Figure 2. There is a greater variability in the excretion of this compound by both normal and hirsute subjects than there is with any of the 11oxygenated adrenal metabolites.

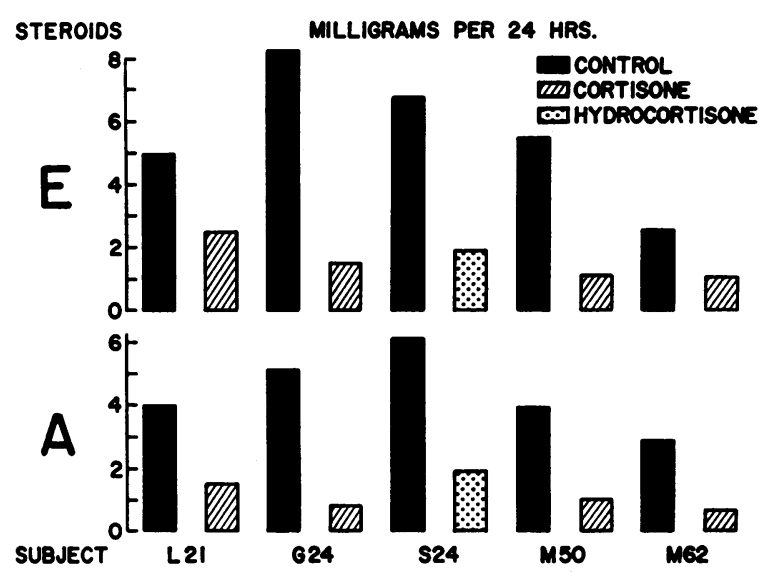

Fig. 4. Effect of Cortisone and Hydrocortisone on the Production of Androsterone (A) and EtioCholanolone (E) By Hirsute Women
Extended methodological surveys indicate that this is not the result of error in technique but the reason for the scatter in results is not understood. There is no obvious correlation between the amount of $D$ and either the 11-desoxysteroids or the 11-oxygenated metabolites.

There was, in general, increased production of 11-oxygenated metabolites by the hirsute women but of a definitely smaller magnitude than that found with the 11-desoxysteroids. Thus, OH-E and $11=\mathrm{OE}$ (which are considered to be derived principally from hydrocortisone) were 50 per cent higher than the level characteristic of normal women; OH-A (which is only a minor product of hydrocortisone metabolism) was 80 per cent higher than the normal level.

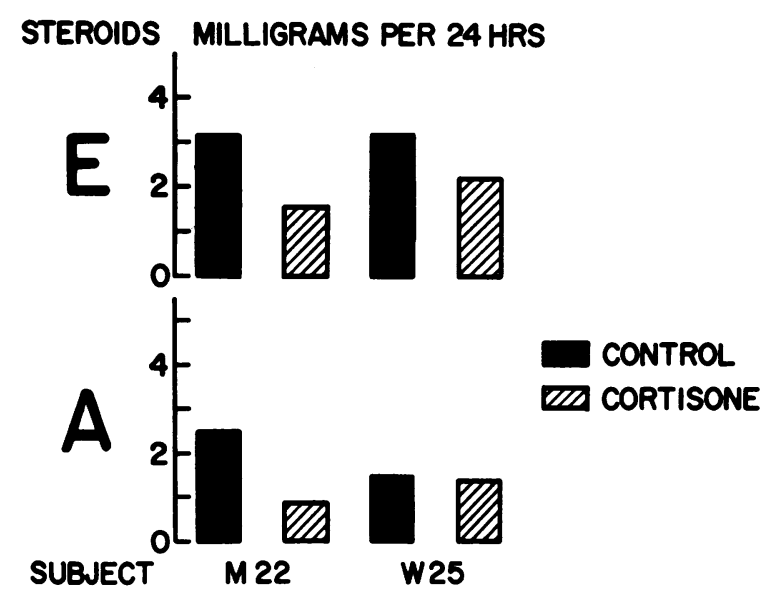

Fig. 5. Effect of Cortisone on the Production of Androsterone (A) and Etiocholanolone (E) BY NORMaL WOMEN

The effect of exogenous cortical steroid on the production of 11-desoxyketosteroids of the hirsute women is shown in Figure 4. There was a significant decrease in the production of these compounds by all subjects. The effect of cortisone administration on $\mathrm{A}$ and $\mathrm{E}$ production in two normal young women is shown in Figure 5 . The results charted are for the third day of cortisone feeding; there was no material alteration in these values by the sixth day.

\section{DISCUSSION}

Examination of the individual urinary steroids revealed quantitatively significant alterations from a normal pattern in each of the hirsute women 
studied. This excessive steroid production is of considerable interest since all of the subjects presented hirsutism but were an otherwise quite heterogeneous group. The detailed results were to a certain extent foreshadowed by scattered reports that "ketosteroids" are sometimes elevated in simple hirsutism (8). Separation of the individual components of "ketosteroids" as in this study, however, permits a specific and plausible interpretation of the endocrine aspects of this disorder. It is emphasized that hirsutism was the only criterion of patient selection. The inclusion of four patients with a later established diagnosis of the Stein-Leventhal syndrome was, in this respect, fortuitous.

The principal steroid alteration demonstrated was an elevated production of androsterone and etiocholanolone (A and $\mathrm{E}$ ). Each of the hirsute women produced abnormally large amounts of these two substances when compared with women of commensurate age; indeed, the amounts found equaled the production of these steroids by young normal men. The significance of this fact is apparent when it is considered that in addition to a probable sex difference in adrenal function, the male gonad definitely contributes a portion of these metabolites.

These observations on steroid production by hirsute women lead necessarily to a consideration of the source, nature and biological properties of the endogenous precursors of these steroids. The evidence is substantial that in women as well as in men the adrenal cortex elaborates the principal precursors of the urinary metabolites studied (2, 9). Among the various facts that can be cited for the adrenal origin of the hormones which are metabolized to $\mathrm{A}$ and $\mathrm{E}$ the following are pertinent: 1) Castrated men and women with intact adrenals continue to produce both $A$ and $E$ (9). These two metabolites, however, are not found in the urine of adrenalectomized and castrated human patients. 2) Women and men markedly increase the production of $\mathrm{A}$ and $\mathrm{E}$ when stimulated with adrenocorticotrophic hormone (ACTH) (2, 10). 3) Normal men and women who have received suppressive doses of cortisone exhibit a significant diminution in these metabolites (10). All these are explicable only in terms of an adrenocortical origin of the hormones that give rise to $\mathrm{A}$ and $\mathrm{E}$. With specific reference to the origin of
$\mathrm{A}$ and $\mathrm{E}$ in the hirsute women examined in this study, the adrenal cortex is demonstrably involved since a fall in production of these compounds to levels observed in normal nonhirsute women was readily achieved with cortisone or hydrocortisone (Figures 4 and 5). The suppression of adrenal activity by cortisone or hydrocortisone administration showed that the hypersecretion of androgen in these women was under pituitary control but whether the adrenal was hypersensitive or the ACTH production was excessive is neither evident nor is it relevant to the conclusions drawn from this study. It should be noted, however, that depression of adrenal function by exogenous steroid occurred in the Stein-Leventhal syndrome (L21, S24) contrary to previous report (11).

From the considerations outlined it may be assumed that the elevated level of $A$ and $E$ in the hirsute women reflected the existence of adrenocortical hyperfunction. The nature of this excessive adrenal secretion can be described in the following terms. The steroid metabolites isolated in abnormal amount were the same compounds that result from the metabolic transformation of known androgens such as $\Delta^{4}$-androstene-3,17dione, dehydroisoandrosterone or testosterone (12-14). Similarly, the principal clinical feature in these women was unmistakably androgenic. Thus both the clinical evidence and the chemical structure of the metabolites are compatible with the interpretation that the adrenocortical secretion in these subjects was characterized by an excessive production of adrenal androgen.

There were other chemical manifestations of adrenal hyperactivity, evidenced by an elevated production of $\mathrm{C}_{19}-11$-oxygenated steroids in several women. In this latter group, together with the increased hydrocortisone metabolites $11=\mathrm{OE}$ and OH-E, most exhibited abnormal amounts of $\mathrm{OH}-\mathrm{A}$, a steroid metabolite of $11 \beta$-hydroxy- $\Delta^{4}$ androstene-3,17-dione (15) which is present in human adrenal vein blood (16). This latter substance is itself weakly androgenic. Thus, the increased adrenal function was not limited to metabolites of 11-desoxysteroid hormones even though this class showed the greater elevation.

The demonstration of adrenocortical hyperactivity in four women with the Stein-Leventhal syndrome is of considerable interest. Previous attempts to study alterations in the adrenal secre- 
tion in this disorder (17) must be reviewed in the light of advances in steroid analysis which permit the recognition of less overt derangements in glandular physiology than are possible by the ordinary clinical assay of neutral "17-ketosteroids." It seems likely that more detailed steroid analyses of the type employed in the present study would reveal significant hormonal alterations in a number of these women. Indeed, these biochemical observations, together with the association of polycystic ovaries with frank adrenal disease $(4,18)$ and the frequent occurrence of hirsutism in the SteinLeventhal syndrome (19), suggest that altered adrenal function, as described here, might be a significant or even primary influence in this disorder.

Accumulated evidence has led to the interpretation that the secretion of the adrenal cortex in the human contains at least two major groups of steroid hormones, either of which can be suppressed or stimulated without material effect upon the other. The experimental basis for this conclusion has been summarized $(20,21)$. In terms of this hypothesis, the biochemical lesion defined by these studies of hirsute women is an adrenal hyperfunction largely limited to the adrenal androgen; hyperactivity of the biosynthetic mechanisms leading to hydrocortisone production, on the other hand, is only a minor feature of this syndrome. If it be granted that increased production of $A$ and $E$ has been demonstrated in this study, it may appear mildly surprising that this is not accompanied by an increased secretion of hydrocortisone and chemically related hormones. Quite apart from the hypothesis presented above, however, the physiological consideration must be borne in mind that these hirsute women do not exhibit signs and symptoms of Cushing's syndrome. If the adrenal hyperfunction were other than the unilateral type proposed, it would necessarily follow that some evidence of hydrocortisone excess would be manifest clinically. That this is not generally the case may be considered confirmatory evidence for the explanation advanced.

The biochemical-clinical correlation described in these patients with hirsutism is suggestive of a causal relationship between the abnormal adrenal secretion and the hypertrichosis. Indeed, if the metabolic fate of the adrenal androgen were similar to that of testosterone in man $(12,22)$, the ex- cessive secretion in these subjects would bring their hormone production into the range of normal males. Such hormonal influence operating constantly over a prolonged period of time seems entirely capable of stimulating and supporting the hypertrichosis in these patients. It is apparent that the unknown biologic potency of the adrenal androgen, and the variety of factors, including genetic ones, that might influence tissue response to hormonal stimulation, are considerations of importance in the interpretation of these data. Moreover, despite the uniformity of the observations in this study it is not certain that the hormonal aberration demonstrated will invariably be evident in all women with idiopathic hirsutism since extrahormonal influences must be variable and complex. Nevertheless, the observations described in this report are definitive of significant adrenocortical hyperfunction and indicate the existence of an important influence on the growth of hair in a considerable number of these patients. ${ }^{3}$

\section{SUMMARY}

A detailed examination of the urinary steroids was made in 13 women with hirsutism, including 4 with associated clinical and pathological findings typical of the Stein-Leventhal syndrome. Excessive production of two adrenal hormone metabolites, androsterone and etiocholanolone, was noted in all subjects together with a lesser but significant elevation in the metabolites of 11-oxygenated hormones.

In the light of previous knowledge concerning the source and physiologic character of the hormonal precursors of these metabolites, it can be presumed that the steroidal aberration manifest in these women was a relative hypersecretion of androgenic hormone, or hormones, from the adrenal cortex. A significant relationship is strongly implied between the excess production of adrenal androgen and the hypertrichosis in these women.

\footnotetext{
${ }^{3}$ Since this manuscript was submitted, Perloff, Hadd, Channick, and Nodine (23) have reported studies of steroid excretion by hirsute women similar to those described in the present communication. Their conclusions confirm the interpretation given to an earlier study (3) and extend the experimental findings to a larger group of women. Their results and conclusions, considered with the present report, leave little doubt that "idiopathic" hirsutism is more properly categorized as a type of adrenal hyperfunction.
} 


\section{REFERENCES}

1. Dobriner, K., Lieberman, S., and Rhoads, C. $P$. Studies in steroid metabolism. I. Methods for the isolation and quantitative estimation of neutral steroids present in human urine. J. biol. Chem. 1948, 172, 241.

2. Kappas, A., and Gallagher, T. F. Studies in steroid metabolism. XXVIII. The $\alpha$-ketosteroid excretion pattern in normal females and the response to ACTH. J. clin. Invest. 1955, 34, 1566.

3. Kappas, A., Pearson, O. H., West, C. D., and Gallagher, T. F. A study of "idiopathic" hirsutism; a transitional adrenal abnormality. J. clin. Endocr. 1956, 16, 517.

4. Du Toit, D. A. H. Polycystic Ovaries, Menstrual Disturbances and Hirsutism; Hyperthecosis. Leiden, Kroese, 1951.

5. Abu-Haydar, N., Laidlaw, J. C., Nusimovich, B., and Sturgis, S. Hyperadrenocorticism and the SteinLeventhal syndrome. J. clin. Endocr. 1954, 14, 766.

6. Goldberg, M. B., Maxwell, A. F., and Smith, P. M. Three unusual endocrinopathies with associated ovarian pathology; I. Ovarian agenesis; II. Precocious puberty; III. Virilism. J. clin. Endocr. 1947, 7, 11.

7. Stein, I. F., and Cohen, M. R. Surgical treatment of bilateral polycystic ovaries-amenorrhea and sterility. Amer. J. Obstet. Gynec. 1939, 38, 465.

8. Dorfman, R. I., and Shipley, R. A. The Androgens. New York, John Wiley and Sons, Inc., 1956, p. 418.

9. Dobriner, K., and Lieberman, S. The metabolism of steroid hormones in humans in A Symposium on Steroid Hormones, .E. S. Gordon, Ed. Madison, University of Wisconsin Press, 1950, p. 46.

10. Kappas, A., Dobriner, K., and Gallagher, T. F. Studies in steroid metabolism. XXVII. A comparison of the steroid response to $\mathrm{ACTH}$ and cortisone in normal young men. $\mathrm{J}$. clin. Invest. $1955,34,1559$.

11. Jailer, J. W., and Vande Wiele, R. L. Studies in hirsutism. I. Urinary excretion of the neutral 17 ketosteroids. Gynaecologia (Basel) 1954, 138, 276.
12. Fukushima, D. K., Dobriner, K., and Gallagher, T. F. Studies with testosterone-d in normal men. J. biol. Chem. 1954, 206, 845.

13. Dorfman, R. I., Wise, J. E., and Shipley, R. A. Metabolism of the steroid hormones: Metabolism of $\Delta^{4}$-androstenedione-3,17, androstanedione-3,17, and androstanediol-3 $(\alpha), 17(\alpha)$ in a hypogonadal man. Endocrinology 1950, 46, 127.

14. Mason, H. L., and Kepler, E. J. Isolation of androsterone, etiocholan-3 $(\alpha)$-ol-17-one, and $\Delta^{5}$-androstene-3 $(\beta), 17(\alpha)$-diol from the urine after administration of dehydroisoandrosterone to a man. J. biol. Chem. 1945, 160, 255.

15. Bradlow, H. L., and Gallagher, T. F. Metabolism of $11 \beta$-hydroxy- $\Delta^{4}$-androstene-3,17-dione in man. J. biol. Chem. 1957, 229, 505.

16. Romanoff, E. B., Hudson, P., and Pincus, G. Isolation of hydrocortisone and corticosterone from human adrenal vein blood. J. clin. Endocr. 1953, 13, 1546.

17. Ingersoll, F. M., and McDermott, W. V., Jr. Bilateral polycystic ovaries, Stein-Leventhal syndrome. Amer. J. Obstet. Gynec. 1950, 60, 117.

18. Discussion of Cushing's Syndrome in Ciba Foundation Colloquia on Endocrinology. Vol. VIII. The Human Adrenal Cortex. Boston, Little, Brown and Company, 1955, p. 522.

19. Stein, I. F. Bilateral polycystic ovaries; significance in sterility. Amer. J. Obstet. Gynec. 1945, 50, 385.

20. Gallagher, T. F. Steroid hormone metabolism and the control of adrenal secretion in The Harvey Lectures. New York, Academic Press Inc., 1957, series LII, p. 1.

21. Gallagher, T. F. On alterations in adrenal function, especially with adrenocortical carcinoma. Cancer Res. 1957, 17, 520.

22. Fukushima, D. K., Bradlow, H. L., Dobriner, K., and Gallagher, T. F. The fate of testosterone infused intravenously in man. J. biol. Chem. 1954, 206 , 863.

23. Perloff, W. H., Hadd, H. E., Channick, B. J., and Nodine, J. H. Hirsutism. Arch. intern. Med. 1957, 100, 981. 